\title{
Tricomoníase: prevalência no gênero feminino em Sergipe no biênio 2004-2005
}

\author{
Trichomoniasis: prevalence in the female gender in 2004-2005 \\ in Sergipe State, Brazil
}

M ayra Santos Almeida ${ }^{1}$

Danilo Souza Argôlo ${ }^{2}$

JoséSodré Almeida Júnior ${ }^{2}$

$M$ alone Santos Pinheiro ${ }^{1}$

Ana M aria Guedes de Brito ${ }^{2}$

\footnotetext{
${ }^{1}$ Laboratório de Produtos Naturais eSintéticos, Instituto de Tecnologiae Pesquisa, Av. Murilo Dantas 300, Farolândia. 49032-490 Aracaju SE. mayfarm@superig.com.br ${ }^{2}$ UniversidadeTiradentes.
}

Abstract Trichomoniasis is a disease caused by the protozoan Trichomonas vaginalis, which initiates a wide variety of clinical manifestations. It may be associated with human immunodeficiency virus, cervical cancer, infertility and other diseases. Its incidence ranges from $20 \%$ up to $40 \%$ in Brazil. The primary channel of transmission is by sexual contact and laboratorial diagnostic may be performed by chain polymerase reaction (CPR), culture medium isolation, fresh vaginal content exam and/or colored by Giemsa and Papanicolau methods. The later has limitations in the detection of pathologies considered sexually transmissible, like Thricomoniasis. This work deals with prevalence of Thricomoniasis in users of laboratories associated with the M inistry of Health, in the age group from 19 up to 44 years old which were submitted to Papanicolau test in 2004-2005 in Sergipe state, Brazil. Results have revealed that among 206,034 users, 7,349 haveshown Thricomoniasis, being 3,788 in 2004 and 3,498 in 2005. It could beobserved that the estimated prevalencein Sergipe in the biennium studied did not corroborate with the Brazilian reality, which may be attributed to the diagnostic executed.

Key words Thricomoniasis, Prevalence, Women, Sergipe
Resumo A tricomoníase é uma protozoose causada pelo Trichomonas vaginalis, que desencadeia uma ampla variedade de manifestações clínicas, podendo estar associada à transmissão do vírus da imunodeficiência humana, câncer cervical, infertilidade, entre outros. N o Brasil, a incidência varia entre 20 e $40 \%$. A via primária de transmissão é pelo contato sexual e o diagnóstico laboratorial pode ser realizado através da Reação de Polimerase em Cadeia (PCR), isolamento em meios de cultura e exame do conteúdo vaginal à fresco e/ ou corados pel os métodos de Giemsa ePapanicolau. Esse último possui limitações na detecção de patologias consideradas DST, a exemplo da tricomoníase. Esse artigo trata da prevalência de tricomoníase em mulheres usuárias dos laboratórios conveniados ao M inistério da Saúde, na faixa etária de 19 a 44 anos, que foram submetidas ao teste de Papanicolau, em 2004-2005, no Estado de Sergipe. Os resultados revelaram que, em 206.034 usuárias, 7.349 apresentaram tricomoníase, sendo que 3.788 em 2004 e 3.498 em 2005. O bservou-sequea prevalência estimada em Sergipe, no biênio estudado, não corrobora com a realidade brasileira, fato esse que pode estar atrelado ao diagnóstico executado.

Palavras-chave Tricomoníase, Prevalência, M uIheres, Sergipe 
Introdução

O Trichomonas vaginalis é um protozoário que foi descrito pelo médico francês Alfred Donné, em 1836. Eleéconsiderado o agenteetiológico da tricomoníase responsabilizado pela infecção se xualmente transmissível não viral mais comum no mundo. A prevalência mundial anual da parasitose acima citada é cerca de 180 milhões de casos, principalmente no gênero feminino e na faixa etária de 15 a 45 anos ${ }^{1,2}$. A pesar da alta ocorrência e dos riscos associados à infecção, pouco ainda éconhecido acerca de sua variabilidade biológica ${ }^{3}$. Esse flagelado vive, principalmente, no muco e secreção vaginal das mulheres; já em homens, pode se colonizar na uretra, próstata e epidídimo e nesses habitates multiplicar-se por divisão binária simples longitudinal, possuindo tropismo, em especial, pelo epitélio escamoso do trato genital. Tem sido associado à transmissão do vírus da imunodeficiência humana (HIV), à doença inflamatória pélvica, ao câncer cervical, a infertilidade, ao parto prematuro e baixo peso de recém-natos de mães infectadas ${ }^{4-8}$. A transmissão desse parasito, em humanos, ocorreprincipalmente pela relação sexual. Entretanto, outros mecanismos de propagação estão envolvidos, a exemplo da veiculação do protozoário através de fômites (de uso pessoal), entre outros, os quais explicam a existência da infecção em re cém-nascido eindivíduos com ausência de atividade sexual ${ }^{9}$. M ediante 0 exposto, esse trabalho buscou avaliar a prevalência da tricomoníase no Estado de Sergipe, através de coleta de dados computadorizados, existentes no Centro de Referência da Mulher, em Aracaju (SE), nas usuárias que, após exame clínico e laboratorial, apre sentavam-se parasitadas por Trichomonas vaginalis, no biênio 2004-2005.

\section{Material emétodos}

A pesquisa de campo retrospectiva foi realizada conforme a Resolução n 196/96 do Conselho Nacional de Saúde e elaborada durante o primeiro semestre de 2006 no Centro de Referência da Mulher (CRM), situado à Avenida Tancredo Neves, 7.255, Jabotiana, Aracaju (SE).

Foi avaliadaa prevalência da tricomoníase em mulheres submetidas ao exame colpocitológico de Papanicolaou nos laboratórios do Estado de Sergipe atrelados ao M inistério da Saúde, bem como o CRM , o qual compila dados dos referidos laboratórios e foi responsável por disponibi- lizá-los através de arquivos computadorizados sobre a citada parasitose no biênio de 2004-2005.

No que tange à amostra, no biênio em Sergipe, foram atendidas e submetidas ao exames clínico e colpocitológico pelo Papanicolau 206.034 mulheres, sendo 103.537 mulheres em 2004 e, em 2005, 102.497. Além das informações acerca da parasitose, trabalhou-se também com as variáveis faixa etária, associações com outras DST e grau de escolaridade para melhor embasamento acerca da prevalência do agravo no Estado de Sergipe.

Foi realizada uma análise descritiva dos dados, na qual as informações coletadas, incluindo as variáveis, foram organizadas e expressas em porcentagem.

\section{Resultados}

A partir das informações levantadas nos arquivos computadorizados do CRM , tornou-se possível a apresentação dos dados que seguem.

No biênio 2004-2005, foram atendidas no estado supracitado esubmetidas ao exame clínico, bem como colpocitológico pelo Papanicolau, 206.034 mulheres, sendo $103.537 \mathrm{em} 2004$ e, em 2005, 102.497 mulheres. Delas, no ano de 2004, $96,34 \%$ apresentaram-se negativas e 3,66 positivas para tricomoníase; já em 2005, observou-se que $96,53 \%$ estavam negativas e $3,47 \%$ positivas para a citada protozoose, conforme demonstra o Gráfico 1.

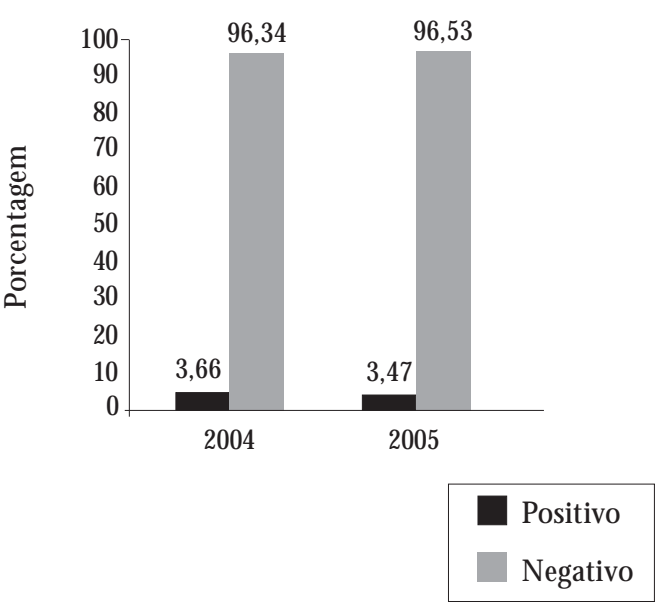

Gráfico 1. Prevalência de mulheres positivas e negativas para tricomoníase no biênio 2004-2005, Aracaju (SE).

Fonte: Centro de Referência da M ulher (CRM ), Aracaju (SE). 
A Tabela 1 diz respeito à distribuição percentual de usuárias infectadas por Trichomonas vaginalis conforme a faixa etária, no biênio 20042005 (SE), na qual se detectou que as maiores prevalências ocorreram entre 14 a 44 anos.

0 Gráfico 2 avalia a concomitância com herpes genital (HSV) e Chlamydia trachomatis nas portadoras de tricomoníase, no Estado de Sergipe, no biênio 2004-2005, no qual se obteve respectivamente $(0,71 \% ; 0,39 \%)$ e $(0,45 \% ; 0,81 \%)$.

\section{Discussão}

Os resultados, no que se refere à prevalência de tricomoníase no Estado de Sergipe, corroboraram com o estudo de Cardoso et al. ${ }^{10}$, realizado no hospital Rômulo Rocha, na Faculdade de Farmácia da U FG, em M ozarlândia (GO), que detectou uma prevalência de $2,23 \%$, e Otarola et al. ${ }^{11}$, que constataram uma positividade para referida parasitose de 4,96\%. No entanto, Rey ${ }^{12}$ ressalta queas estatísticas nos países em desenvolvimento, a exemplo do Brasil, registram taxas de tricomoníase oscilando entre $20 \%$ e $40 \%$ no gênero feminino, divergindo dos resultados acima citados.

Quanto à faixa etária, relatam Gerbase ${ }^{13}$, Barrio et al $^{14}$ e De Carli ${ }^{8}$ que os casos de tricomoníasemundial acometem principalmenteo gênero feminino na faixa etária compreendida entre 15 e 49 anos; esses resultados coadunam com os

Tabela 1. Prevalência conforme a faixa etária das mulheres com tricomoníase no biênio 2004-2005.

\begin{tabular}{lrr}
\hline $\begin{array}{c}\text { Distribuição das mulheres } \\
\text { com tricomoníase por } \\
\text { faixa etária }\end{array}$ & $\begin{array}{c}\text { Porcentagem } \\
\text { (\%) } 2004\end{array}$ & $\begin{array}{c}\text { Porcentagem } \\
\text { (\%) } 2005\end{array}$ \\
\hline $12-\mid 14$ & 0,13 & 0,24 \\
$14-19$ & 5,97 & 5,94 \\
$19-\mid 24$ & 15,40 & 13,47 \\
$24-\mid 29$ & 15,66 & 15,43 \\
$29-\mid 34$ & 16,32 & 14,10 \\
$34-\mid 39$ & 14,45 & 13,39 \\
$39-\mid 44$ & 11,54 & 12,23 \\
$44-\mid 49$ & 8,90 & 8,87 \\
$49-\mid 54$ & 5,71 & 5,41 \\
$54-\mid 59$ & 2,85 & 2,46 \\
$59-\mid 64$ & 1,56 & 1,43 \\
$>64$ & 1,51 & 0,85 \\
\hline
\end{tabular}

Fonte: Centro de Referência da M ulher (CRM ), Aracaju (SE). apresentados nessa pesquisa. Provavelmente, essa ocorrência possa estar atrelada ao comportamento sexual efalta de conscientização quanto à prevenção de doenças sexualmente transmissíveis, bem como, segundo Lehker ${ }^{5}$ eN eves ${ }^{15}$, alterações que podem vir a ocorrer no meio vaginal, principalmente no período menstrual, tais como variações de pH , diminuição na produção deglicogênio, intensa descamação do tecido epitelial e oscilações hormonais, favorecendo a implantação, multiplicação ecolonização do protozoário. Afirmam Petrin et al. ${ }^{16}$ que a tricomoníase pode ser considerada um agravo à idade reprodutiva; raramente as manifestações clínicas são observadas antes da menarca e pós-menopausa.

A análise do nível de escolaridade das portadoras de tricomoníase, no Estado de Sergipe, revelou que o maior percentual encontrava-se entre as que possuíam o ensino fundamental incompleto $(62,72 \%)$, no biênio avaliado, dados esses consonantes com os observados por M otta et al. ${ }^{17}$, em um estudo semel hante a esse realizado no H ospital das Clínicas (SP), demonstrando que cerca de $59,2 \%$ das pacientes investigadas possuíam o nível de escolaridade supracitado. Esse dado éum indício de que, ao se implementar programas preventivos relacionados às doen-

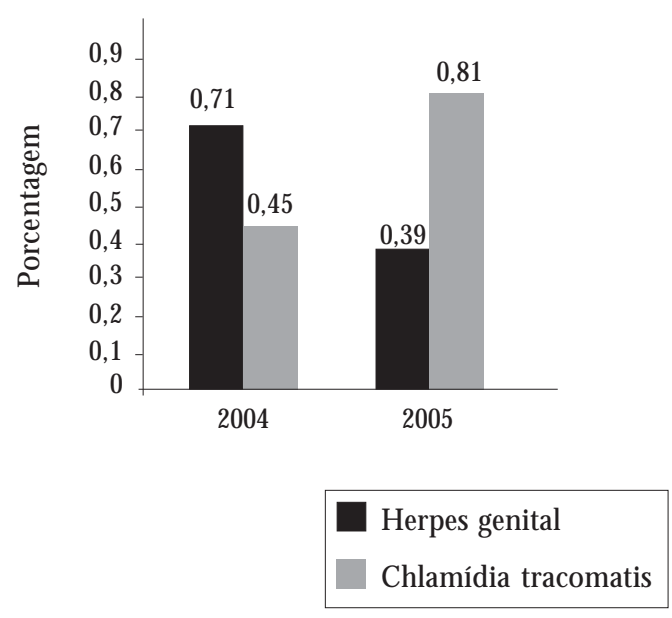

Gráfico 2. Concomitância da prevalência de herpes genital e Chlamidia trachomatis nas portadoras de tricomoníase no biênio de 2004-2005, Aracaju (SE).

Fonte: Centro de Referência da M ulher (CRM )Aracaju (SE). 
ças sexualmentetransmissíveis, a exemplo da tricomoníase, faz-se necessário previamente o re conhecimento da população a ser trabalhada.

No CRM, bem como nos demais laboratórios de diagnósticos atrelados ao M inistério da Saúde, é utilizado tanto para câncer do colo uterino como para as DST o exame colpocitológico ou teste de Papanicolau. Reportam Pinho et al. ${ }^{18}$ queessetesteéadequado para detectar câncer do colo uterino precoce. Já M erck-Feld et al. ${ }^{19}$ postularam que, além da possibilidade de avaliação dealterações inflamatórias eneoplásicas, elepermite observar a presença ou não de bioagentes específicos, como fungos e outros microorganismos, incluindo o protozoário objeto desse estudo. No entanto, Silva Filho ${ }^{20}$ sinaliza para um percentual de falha em torno de $30 \%$ a $40 \%$ quando se utiliza tal teste para a identificação de flagelados; 0 autor concluiu ainda que, para a avaliação de elementos vaginais não epiteliais, 0 melhor método éa citologia direta à fresco. Lobo et al. ${ }^{21}$ realizaram um estudo comparativo entre o diagnóstico da tricomoníase através do exame do conteúdo vaginal pelo PCR (Reação em Cadeia da Polimerase) e achados citológicos pelo teste de Papanicolau em uma amostra populacional no Distrito Federal, cujo resultado demonstrou que o teste acima citado apresentou uma sensibilidade de apenas $60,7 \%$ para o Trichomonas vaginalis, indicando, conforme os autores, ser inadequado para esse protozoário. Os dados deprevalência obtidos nesse trabal ho tal vez este jam sendo comprometidos, pois o CRM só utiliza o teste de Papanicolau.

Quanto à concomitância do Trichomonas vaginalis e Chlamydia trachomatis encontrada nessa pesquisa, foram discrepantes aos mencionados pela Agência Nacional de Vigilância Sanitária ${ }^{22}$, que constata uma ocorrência da coinfecção de cerca de $15 \%$.

\section{Colaboradores}

MS Almeida, DS Argôlo, JS Almeida Junior, M S Pinheiro e AM G Brito participaram igualmente de todas as etapas da elaboração do artigo.
Já a correlação com o vírus do herpes genital está associada ao mecanismo semelhante ao de acesso à corrente sanguínea, efetuado ao vírus HIV. Rosset et al. ${ }^{23}$ explicam que a resposta inflamatória induzida pelo Trichomonas vaginalis favorece uma infiltração de células de defesa (leucócitos, linfócitos e macrófagos), causando pontos hemorrágicos na mucosa uterina, permitindo 0 acesso direto do vírus ao organismo. Lupi ${ }^{24}$ relata, ainda, que a transmissão do vírus da herpes genital realmente ocorre ao longo das superfícies mucosas ou das soluções de continuidade da pele e é facilitada quando o sistema imunológico encontra-se suprimido. Cotch ${ }^{25}$ ressalta a possibilidade desse protozoário atuar também como vetor para outros patógenos.

\section{Conclusão}

Concluiu-sequea prevalência estimada para tricomoníase, no Estado de Sergipe, nos anos de 2004 e 2005, foi de 3,66\% e 3,47\%, respectivamente.

Acredita-se que, em virtude da utilização do teste de Papanicolau para diagnosticar essa parasitose pelo CRM e laboratórios de colpocitologia atrelados ao M inistério da Saúde e esse não apresentar uma boa sensibilidade de detecção do Trichomonas vaginalis, bem como os erros humanos que podem vir a acontecer, somados aos casos que podem não terem sido captados, essa prevalência pode não ter refletido a real situação da parasitose supracitada no Estado.

Portanto, sugere-se uma reavaliação da situação como um todo, inclusivea eficácia dos programas preventivos, para que se obtenham dados fidedignos que venham a contribuir de forma consistente ao monitoramento desse agravo à saúde, com a meta de mel horar a qualidade de vida das sergipanas. 


\section{Referências}

1. Rein MF. Trichomonas vaginalis. In: Mandell GL, Bennet JE, Dolin R, editors. Principles and practice of infectious diseases. New York: Churchill Livingstone; 1995. p. 2493-2497.

2. U rbanetz AA, Bertasi S, Zandoná S, Petry ACM Quadro clínico e métodos diagnósticos das vulvovaginites mais frequentes. Femina 2002; 30 (2):117-123.

3. Shimp L. A vaginal and vulvovaginal disorders. In: Berardi RR, DeSimone EM, Newton GD, Oszko M A, Popovich NG, Rollins CJ, Shimp LA, Tietze KJ, editors. Handbook of nonprescription drugs. Washington, D.C.: American Pharmaceutical Association; 2002. p.129-147.

4. Heine $P, M$ cgregor JA. Trichomonas vaginalis: a reemerging pathogen. Clin O bstet Gynecol 1993; 36:137144.

5. Lehker MW, Alderete JF. Biology of trichomonosis. Curr Opin Infect Dis 2000; 13:37-45.

6. M endoza-Lopez MR, Becerril-Garcia C, Fattel-Fazenda LV, Avila-Gonzalez L, Ruíz-Tachiquín ME, Ortega-Lopez J, Arroyo R. CP 30, a Cysteine Proteinase Involved in Trichomonas vaginalis Cytoadherence. Infect Immun 2000; 68(9):4907-4912.

7. Maciel GP, Tasca T, De Carli GA. Aspectos clínicos, patogênese e diagnóstico de Trichomonas vaginalis. J. Bras. Patol. M ed. Lab 2004; 40(3):152-160.

8. De Carli GA. Trichomonas. In: Neves DP, organizador. Parasitologia humana. São Paulo: Atheneu; 2004. p. 101-105.

9. H offman DJ, Brown GD, Wirth FH, Gebert BS, Bailey $\mathrm{CL}$, Anday EK. Urinary tract infection with Trichomonas vaginalis in a premature newborn infant and the development of chronic lung disease. J. Perinatol 2003; 23:59-61.

10. Cardoso AC, Araújo LV, Silva PR,Gouveia DDS, Freitas RC, Tavares SBN, Amaral RG, Garrote CFD. Prevenção do câncer do colo do útero no município de Mozarlâdia-GO. Rev Eletrônica de Farmácia 2005; 2(2):41-43.

11. Otarola CU, Briceno JF, Bahamondes M M I, Muñoz RM, Lorca M H. Frecuencia de Trichomonas vaginalis detectadas mediante Papanicolaou em cuatro servicios de salud, 1997-2002. Rev Chil Obstet Ginecol 2005; 70(1):3-7.

12. Rey L. Bases da parasitologia médica. 2 a ed. Rio de Janeiro: Guanabara Koogan; 2002.

13. Gerbase AC, Rowley JT, Mertens TE. Global prevalence and incidence estimates selected curable STDs. Sex Transm Inf 1998; 74(suppl.1):S12-S16.

14. Barrio AG, Nogalr JJ, Montero PD, Rodríguez GE, Romero FE, Escario J. A Biological variability in clinical isolates of Trichomonas vaginalis. M em Inst Oswaldo Cruz 2002; 97:893-896.
15. Neves DP. Parasitologia humana. 11ạ ed. São Paulo: Atheneu; 2005.

16. Petrin D, Delgaty K, Bhatt R, Garber G. Clinical and microbiological aspects of Trichomonas vaginalis. Clin Microbiol Rev 1998; 11:300-317.

17. Motta EV, Fonseca AM, Bagnoli VR, Ramos LO, Pinotti JA. Colpocitologia em ambulatório de ginecologia preventiva. Rev. Assoc. Med. Bras. 2001; 47(4):302-310.

18. Pinho AA, Mattos M CFI. Validade da citologia cervicovaginal na detecção de lesões pré-neoplásicas e neoplásicas de colo de útero. J. Bras. Patol. M ed. Lab 2002; 38(3):225-231.

19. Merki-Feld GS, Lebeda E, Hogg B, Keller PJ. The incidence of Actinomyces-like organisms in Papanicolaou-stained smears of copper and levonorgestrel-releasing intrauterine devices. Contraception 2000; 61(6):365-368.

20. Silva Filho AR. Citologia vaginal a fresco na gravidez: correlação com a citologia corada pela técnica de Papanicolaou. Rev. Bras. Ginecol. O bstet 2004; 26(7):509-515.

21. Lobo TT, Feijó G, Carvalho SE, Costa PL, Chagas C, Xavier J, Simões AB. A Comparative Evaluation of the Papanicolaou Test for the Diagnosis of Trichomoniasis. Sex Transm Dis 2003; 30(9):694-699.

22. Agência Nacional de Vigilância Sanitária. Principais Síndromes Infecciosas. M ódulo 1. [site da Internet] 2004 [acessado 2006 mai]. Disponível em: http:/ /www.anvisa.gov.br/servicosaude/microbiologia/ mod_1_2004.pdf

23. Rosset $\bar{I}$, Tasca T, Tessele PM, Carli GA. Scanning electron microscopy in the investigation on the in vitro hemolytic activity of Tricomonas vaginalis. Parasitol Res 2002; 88:356-359.

24. Lupi O. Imunoprofilaxia anti-herpética utilizando vírus geneticamente modificado: vacina DISC. An. Bras. Dermatol 2003; 78(3):345-353.

25. Cotch M F, Pastorek JG 2nd, Nugent RP, Hillier SL, Gibbs RS, Martin DH, Eschenbach DA, Edelman R, Carey JC, Regan JA, Krohn MA, Klebanoff MA, Rao AV, Rhoads GG. Trichomonas vaginalis associated with low birth weight and preterm delivery. Sex Transm Dis 1997; 24:353-360.

Artigo apresentado em 23/12/2007

Aprovado em 02/10/2008

Versão final apresentada em 29/10/2008 